\title{
Teaching Critical Thinking Skills in Sulaimani City High Schools: Challenges and Obstacles
}

\author{
Azeez Raouf Abdulazeez \\ Translation Department, College of Languages, Cihan University, Sulaimani, Kurdistan \\ Region, Iraq. \\ E-mail: aziz.raouf@ sulicihan.edu.krd

\section{Sirwan Abdulkarim Ali} \\ Department of English, College of Languages, Soran University, Soran, Kurdistan Region, \\ Iraq. \\ E-mail: Sirwan.ali@soran.edu.iq
}

\begin{abstract}
:
This study addresses teaching critical thinking and problem-solving skills and their impact in high schools of the Kurdistan Region. The basic definitions and strategies of these skills are presented along with different perspectives to closely examine the impacts and the challenges facing both learners and educators. Investigating the role of teachers and their views about the challenges they face is the main question of this study, explored though a semi-structured interview method. The study reveals that teaching critical thinking skills is a crucial component of our education system, and the regional stakeholders have reformed the education system in Kurdistan accordingly during the past five decades. The identified challenges are discussed in this paper to show the significance of a well-planned reformation in teaching methods to promote critical thinking skills via modern strategies and methods.
\end{abstract}

Keywords: Critical Thinking, Teachers' Role, Modernised Education. 


\section{Introduction:}

This paper deals with promoting critical thinking in schools of the Kurdistan region, highlighting the common challenges facing teachers and students. An overview of essential literature, methodology, aims, research questions, and etymology of the concept of critical thinking is presented. The data was collected through personal, semi-structured interviews with ten teachers with five to ten years of experience. A review of significant literature of previous studies is presented with recognisable academic references to support the claims presented by the paper. In addition to the concluding thoughts, crucial comments and recommendations are proposed for education experts and reformers in Kurdistan. The paper demonstrates practical recommendations to improve teaching of critical thinking and problem-solving among students.

There is more than one definition of critical thinking skills, spanning various interpretations of the concept and its historical terminology. Educators and trainers have different definitions, opinions, and readings for practising critical thinking skills. Elder and Paul (2019) define the concept as a mode of thinking about any topic, content, or a problem to develop one's personal thinking through skilful methods to analyse, assess, and reconstruct the topic. They also highlight critical thinking as self-directed, selfdisciplined, self-monitored, and self-corrective thinking. This definition is more relevent to the aims and objectives of this study because the current system of education in the Kurdistan region presumably inspires learner-centred approach (Vernez et al., 2016). Therefore, learning skills are expected to be promoted among the Kurdish educators with a view to thorough, higher standards of quality and mindful instructions that foster effective problem-solving capabilities and critical thinking skills.

Moreover, Elder and Paul (2020) argue that etymologically the phrase "critical thinking" is of ancient Greek origins and implies the development of "discerning judgment based on standards". The term is etymologically derived from two Greek roots: "kriticos", meaning discerning judgment, and "kriterion", meaning standards. This study deals with the modern interpretations of the concept as a creative means to think, question, analyse and assess thoughts, events, and assumptions to enhance teaching critical strategies among high school teachers.

Diemer et al. (2016) state "as oppressed peoples' thinking about and understanding of their social conditions developed, their views of themselves in relation to society also developed". This means that individuals' critical thinking skills can define their social position as they become more open-minded discovering their constrained social conditions and become familiar with their own mental progress. Accordingly, developing critical thinking skills is another way to move toward healthy social reform. Additionally, Freire (2009) adds "the humanist, revolutionary educator" (p. ) can productively involve students in the process and unify their teaching skills with the students learning achievements to create "the quest for mutual humanization". These scholars describe the social significance of learning critical thinking skills as one of the basic tools in education. Additionally, Freire (2009) considers education aimless without healthy debates and group discussions managed by the educators and successful teachers who offer time to student to express their thoughts and perspectives.

Ennis (1998) claims that another aspect of the concept is demonstrating the mental independence and function, considering the process as a mental activity and learning practice. In other words, the students can develop their critical thinking skills via mentally practicing the freedom of thinking and expressing their opinions without fear of culturally biased thoughts. This definition is significant for Kurdish educators because it includes differences in levels of socio-economic status, race, religion, ethnicity, language, or gender because culturally biased viewpoint establishes myths and stereotypes of cultures and possibly motivates racial and ethnic profiling. 
In addition, Peter and Gittens (2015) suggest simplified approaches for the teachers to "deliver the core concepts of critical thinking in a way that students can easily understand". The reason for this simplification is to further engage students in group discussions by incorporating modernised techniques and information technology with examples from the wide range of real-life material. This paper is more concerned about the purposeful process of learning these skills through interpretation, evaluation and analysis derived from factual evidence and data to be engaged in discussion and questioning thoughts.

Finally, Paul (2005) believes that "only when those designing professional development programs have a substantive concept of critical thinking" and he further explains that an individual "is a critical thinker to the extent that he or she regularly improves thinking by studying and critiquing it" (p. 28). His view meets this study's objective as looking for Kurdish teacher who work to develop their field thinking critically and apply their skills to thoughts.

Teaching critical thinking can have many advantages for learners and eventually for the local community and future generation. The concept is common and, in some sources, "thinking outside the box" is used as an equivalent of critical thinking (Walker, 2015) but the question is "what do we mean by promoting critical thinking?" or "how do we practise the skill?" This paper examines teachers' perspectives to identify the barriers and clarify any ambiguities or misunderstanding about the concept. Generally, people are familiar with the concept as the process of analysing facts and revisiting thoughts to establish more logical judgement, but the main idea is to think differently and present new thoughts or discover different angles of the same thought.

(Dunn, 2015) highlights many of the advantages of promoting this skill, such as offering reliable information for decision making, offering individuals flexibility to analyse answers on board or solutions, presenting different views, and giving individuals opportunities to become a leader. Nevertheless, critical thinking can have disadvantages and misuses as can any other method, as outlined by (Gray, 2010), including personal judgments, viewing people as anti-social, difficulties to accept diverse thoughts, stress caused by the opposite opinion, and generating the wrong impression.

\section{Literature Review:}

Haber (2020) states that critical thinking "can be used effectively in situations where an informed decision would be likely to produce the most beneficial results". Accordingly, schools are expected to be the most appropriate environment for this activity. The promotion of critical thinking is one of the principal roles of teachers and it is an effective teaching tool. As a concept, critical thinking becomes an indispensable element in the process of education in most developing countries. This paper investigates the position of critical thinking and the academic studies in this field to promote the skill as an educational method in the schools of the Kurdistan Region. In the developing countries, as Hattie (2012) argues, educational institutions pay further attention to critical and logical thinking skills within their educational intuitions via facilitating critical thinking practices, classroom debates and discussion, evaluation, and comparison of the different levels of learning outcomes before the high school graduation phase.

Moreover, Browne and Keeley (2007) conclude that students need to focus on the field of information and technology to establish a critical view to measure social interactions, effective communication and complex topics with reference to the different skills of critical thinking. Additionally, they find teachers and school the best tools to facilitate and promote the learning skills including critical thinking. Chase et al. (2020) assume that "thinking outside the box" can be the first preliminary step towards 
establishing critical thinking skills because teachers, educators, and trainers or recruiters associate critical thinking with "thinking outside the box" during early age. They also consider "thinking outside the box" to be an essential skill at a specific strategic level of education to obtain an overall view about educational objectives and learning outcomes. However, Allchin (2017), on the other hand, agrees that thinking too much outside the box may commands the brain to miss significant facts and sometimes develops objectional methods to any suggested thought. In this case, as discussed by Greenberg et al. (2021), teachers and trainers need to play a healthy shepherding role to promote critical thinking and objective contributions to knowledge positively.

The Ministry of Education in the Kurdistan region has reviewed several revival efforts to modernise the educational system in the region and every attempt demonstrated specific advantages and unhelpful disadvantages. One of the main advantages of modernising the educational system is the intentions to promote critical thinking, as Schuster (2019) argues that critical thinking, problem solving skills and decision making are complementary skills to add knowledge.

An overview of the reformations in the educational system in the region displays a meaningful development of the educational system and offers further understanding with more crucial reasons to promote critical thinking skills among the Kurdish students. For instance, students in modern education systems can proceed with learning tools during flexible timings including the emergence of online platforms, whereas in traditional education systems the timing was fixed. Secondly, teachers used to play the role of a solo guide in the process of learning and the instructions were structured as subject-centred approach. As Klein (2006) highlights, teachers used to deliver directions and students who used to be defined as information-receivers, focused on the basic educational practices, and expected students to master the academic learning in the core subjects of math, reading, writing, science, and social studies. Generally, students' thoughts and opinions were guided, and they were asked to shadow their teachers and behave themselves in the presence of their teachers, otherwise disciplinary actions would be taken.

On the contrary, the modern approaches of education inspire student-centred learning, in which students are allowed to offer additional contributions to finalise decisions demonstrating their capacity to take leading roles. Information technology has transformed the learning process into a different level where educators are required to facilitate diverse methods and techniques to expand students' performance by developing self-confidence and creating a positive mind-set through goal setting, positive self-talk, visualization, imagery, and self-efficacy (Karwowski and Brzeski, 2017).

Additionally, Yates (1990) believes that building an academic community to review the progress of successful teachers in the modern world highlights the role of teachers in developing skills of critical thinking. Hence, productive, effective teachers from the modern education system's perspective are those educators who can develop learning and creative thinking skills and encourage students to develop problemsolving skills and create competitions inside the class and among the student-groups. Connelly and Clandinin (2004) presents various teaching and learning methods to analyse, imagine, assess, and discuss but not limited to the teacher's role. The successful facilitator can offer the students opportunity to take charge of activities, at the lower levels of education or as it is labelled as Basic Education level in the Kurdistan region.

Moreover, Connelly and Clandinin (2004) conclude that students are identified as talented education purchasers; for example, the third-grade student is familiar with five years of learning and teaching activities, and the eighth-grade high school sophomore has around ten years of similar experience. Therefore, as this study reveals, promoting critical thinking skills offers veteran students the freedom to 
learn the skills that best work for them, the same as experienced teachers, because they have been with their teachers for ten years. Therefore, teachers need to follow incorporated pedagogical strategies that can be identified and clarified by the stakeholders in the field of education.

\section{Methodology:}

The main method in this study includes semi-structured interviews as the means of data collection. Conducting the interviews via face-to-face, or via phone calls or video calls, the subsequent considerations of research ethics and academic interpretations to the interviewee's opinions were taken into considerations. The tools, training courses and practices that are facilitated for the teachers and students via personal interviews and queries were organised by the researchers. The number of interviewees is ten, including both genders, with minimum of five years teaching experience. According to (Whiting, 2008), interview is the most suitable method of data collection in this field, and so this method was practised to gather and preserve the raw data, field-notes, and audio-recordings in the form of English transcriptions and processed according to international standards of research ethics.

Interviewing is one of the best methods for data collection and the reason can be justified through developing the academic context for conceptualizing the role of the Kurdish teachers in promoting critical thinking and problem-solving skills. Basically, this method can directly address the influences of teachers on the current knowledge and the theoretical positions that dominate in the process. Moreover, this method is vital to explore the teachers' interactions with the students and their views to improve and expand the students share in the process. Masats (2017) highlights the significance of interviews and more specifically semi-structured interviews due to their flexibility, as researchers can obtain multi-layered data in various dimensions.

Accordingly, this paper has approached the question of the teacher's role from diverse intersecting perspectives. The analysis reveals the role of teachers in promoting and facilitating group discussion and debates to conceptualise critical thinking and problem-solving skills among the Kurdish class students. As the outcomes will demonstrate the interview method effectively functioned and contributed to the purpose of the study because selected quotes have been cited for further elaboration. The interviewees in this study are from both genders teaching at basic education and high schools in Sulaimani province with a minimum of five years of teaching experience.

\section{Aim and Research Questions:}

The aim of this study is to explore the role of the teachers in promoting critical these skills among the students in basic education and high schools, addressing the advantages, disadvantages, and difficulties facing both teachers and students during the process. The description of the role of teachers in cascading these significant skills and engaging the students is further aim of the study. Additionally, the significance of promoting these skills, as mentioned by Vernez et al. (2016) is crucial for the local community, and the study's respondents highlighted this need. The interviewees' viewpoints effectively identified the fundamental challenges facing the learners not only educators. Also, the paper provides further suggestions and recommendations concluded from the study to establish active critical thinking skills as part of the Ministry of Education's ongoing improvement program.

This paper has examined these skills through interviews conducted with teachers among the schools in Kurdistan, because the present era promotes critical thinking skills and views different aspects of life's realities through discovering similarities and acknowledging the differences. 
The research questions of this study were:

* What is the role of teachers in promoting the concept of critical thinking in their classes?

* What are the main strategies used for promoting critical thinking?

* What are the challenges facing students and teachers while fostering the process?

This study administered self-designed semi-structured interviews to collect more consistent information from reliable sources. The study addressed ten participants of teaching staff and educators with more than five years of teaching experience within the governorate of Sulaimani. The interviews covered participants' views, experience, qualities, preferences, thoughts, opinions, and experience regarding practicing critical thinking skills among Kurdish high school students. The approximate time the interview was sixty minutes, and the interviewees presented effective data because the semi-structured interview offered a considerable amount of flexibility to probe the teacher' perspectives along with maintaining basic interview structure and themes.

The current tool helped the researcher to remain focused on the objectives of the analysis, promoting critical thinking skills, so that reliable data was collected via these interviews. The main questions addressed teachers' contractual obligation to practise critical thinking skills in the class as the basis of their lessons and the difficulties facing them and the learners. The questions were clear and easy to understand, and all the details were recorded and transcribed but kept confidential for ethical reasons.

The paper addresses the difficulties facing Kurdish teachers in basic education and high schools and questions the complicated barriers and modern approaches to assist teachers to act as facilitators. This study responds to further clarifications about the teacher's role in facilitating contemporary skills at different levels of education. There are invisible gaps in student-centred approach and the learning process, gaps which (Driscoll and Wood, 2007) suggest teachers can close by facilitating and promoting critical thinking and problem-solving skills among the learners. Additionally, the study demonstrates some administrative issues, social, cultural, and pedagogical factors that directly influence the process of learning and teaching. This paper explores the challenges facing both educators and learners through addressing small groups of learners, providing healthy academic environment, and equipping teachers with best professional development programs.

\section{Teaching Strategies:}

According to Brookfield (2011), there are selected strategies and techniques to promote critical thinking, through which the emphasis goes to learners and increasing their independence. Although critical thinking, academic debate, problem solving, and decision-making skills are studied at universities through different levels, this paper addresses high school teaching staff to promote these skills. In modern societies, as discussed by Samuel (2019), teachers are not viewed as holy guides anymore; rather they function as facilitators encouraging learners to apply critical thinking and problem-solving skills. The main skills suggested by the scholars are:

- Encouraging learners to ask questions: Paul (2005) suggests that educators can facilitate asking questions and accepting more than one reality to enhance deeper thinking and the finding of different perspectives.

- Encouraging contribution to decision-making process: Ennis (1998) notes that learners need to avoid copying information without assessing its reliability. Future generations will present different thoughts due to the individuals' independent lifestyles. 
- Encouraging learners to work in small groups is essential because large numbers in classes hinder the promotion of critical thinking. Brookfield (2011) refers to this skill as part of the process of promoting these skills and through which learners exchange thoughts, debates, and arguments.

- Encouraging learners to incorporate different points of view is another effective method and it is considered as the core element of the process of dynamic thinking, appreciating, and examining diverse perspectives. Reinforcing and developing this progressively contributes to promoting learners critical thinking skills (MacRitchie, 2018).

- Encouraging learners to connect different ideas to suggest solutions for problems is another tool that teachers can make use of. Learners' skills can be developed through experiencing novel thoughts and creating new environments especially when working in small groups, and "dismantle the limitations that collectivist ideologies" may present (Dzenovska, 2018).

- Encouraging learners to exercise creativity is another favorite method among teachers, who inspire critical thinking skills. Learners are advised to practice and imagine going beyond the walls of the classroom and school boarders to explore the digital tools, which can support creativity, promote student voice, and increase student engagement (Chemi, 2017).

\section{Analysis:}

The study gathered data from ten selected high school teachers, including both genders, with five to ten years' experience. The semi-structured interview focused on the strategies for promoting critical thinking. The participants (six male and four female teachers) had flexibility to move between questions but maintain consistency while answering the questions. The recording and English scripts of the interviews are preserved by the researcher within the scope of research ethics and standards.

The participants offered significant data through their answers, comments and suggestions. The answers cited below provide the most significant quotes by the participants. The language in the quotes has not been corrected.

T1: "In my opinion, promoting critical thinking in our schools is highly significant but there are some obvious obstacles for its application. For example, students' family background and educational environment can play negative role. They are hesitant and lack self-confidence to express their thoughts and opinions due to the dominant environment they brought up with."

The family culture of obedience is one of the obstacles because showing objections to elder's opinion is not allowed due to family values; therefore, the student struggles to view critical thinking skills as opportunity to express differences.

T2: "In my opinion, the authorities and the education system did not offer sufficient support to promote critical thinking and problem-solving skills because it could be an independent subject within the curriculum."

This view highlights developing critical thinking materials through developing and designing curriculum materials. Sharing students' interests in developing their skills should be seen as part of policy makers' obligations.

T3: "School environment is another obstacle faces developing critical thinking skills such as limited time, teachers overloaded working hours, insufficient classrooms, access to internet, air-conditioning 
and electric power, ...etc." the participant feels that the digitalised world of education demands more logistic and technical support while currently the school's buildings function ineffectively. The logistic supplies are progressively significant to overcome the challenges facing educators and learners."

T4: "The financial hardship we experience because of the late and defective payments directly affects the process of teaching and learning. Our rights are generally violated but our responsibilities have been over-emphasized in one place or another. Despite the strikes and demonstrations, teachers are unable to ask for their rights, how can we promote critical thinking skills."

Unlike others, this participant highlights the teachers' personal challenges and the impact of delayed salaries, the reduced monthly amounts, and other social benefits. This mentioned factor directly affects the quality of teaching in general due to inadequate lesson planning, weak performance of student assessment tools, insufficient teaching methods and attendance, unsatisfactory classroom management policy.

T5: "It is necessary to reduce the number of students in classrooms to at least ten to twelve students so that we can create groups and promote critical thinking skills."

Facilitating discussions and group work among large number of students becomes impractical, so classes need to be divided into small groups to achieve effective learning outcomes and develop critical thinking and problem-solving skills.

T6: "Policy makers and stakeholders in Kurdistan have not prioritized developing these skills, the large number of students and reduced time in the classes diminishes he ability to stress on critical thinking skills."

The participant highlights the aforementioned factors by other participants including the excess number of students. She also reveals that the officials' neglect of policy in Kurdistan is another obstacle because modernised learning outcomes demand further well-organised financial and logistic support.

T7: "Critical thinking skills are inapplicable teaching techniques in our classes due to unsuccessful assessment tools and grading patterns. These are massive factors that debilitate developing teachings skills because students are more concerned with their grades and markings rather than developing critical thinking skills."

This participant underscores one of the most significant gaps including the assessment scheme and policies. Accordingly, the teachers' task becomes more complicated while the students' goals are based upon processing the assessment techniques. This mode of thinking is difficult to change because the reasons rests outside the control of students and/or teachers.

T8: "Individuals in Kurdistan region have developed the culture of praise and evolving yes-person rather than criticising because it did become common yet. Although, teaching critical thinking skills is highly crucial."

Aside from the consideration of time, energy and professional teaching techniques, the participant raised this conundrum of teaching and learning as pointing to a yes-person culture. Many stakeholders in the Kurdistan region claim open-door policy, but they regularly side-step feedback. While in the prevailing decision-making culture, healthy debate is unusual.

T9: "In my opinion, teaching critical thinking and problem-solving skills is very important.

Personally, I pay more attention to discussion, questioning, and class activities in the classroom, 
hoping to tolerate the concept and developing skills by teachers to generate diversity and acceptance."

An enthusiastic feeling to develop the skills intersects with personal ambitions hoping to produce open-minded generation via discovering students' talents. Moreover, the participant views developing these skills as part of teachers' responsibility. His personal experience shows that several techniques can help developing these skills, like discussions and questions and class activities.

T10: "The education system in Kurdistan requires more professional improvement. The traditional education system of duplicating information and teachers' explanation require revisions. The modern education system with student-centred learning demand students' contributions and developing critical thinking skills to have educated and open-minded generation."

The participant considers the modern student-centred teaching system to be more appropriate to develop critical thinking skills because it includes students in preparations, implementation, and evaluations. Engaging students in these activities places more responsibility on them and assists them to think critically and suggest solutions for their problems. In brief, teachers play significant role in teaching critical thinking skills, they can make these skills as vital components of their instructional design. As educators, they can evaluate information, the reliability of its sources, and information biases. An overview of the data collected shows that the teachers face a variety of challenges. The challenges presented by the teachers show that teacher can play the role of facilitator with the least possible interference in the process of fostering critical thinking skills because it comes in line with the learner's independent thinking and problem-solving skills.

\section{Findings:}

The findings of this study become exciting when comparing the interviewees' responses, as they responses corroborated each other in their complete agreement with the necessity and objectivity of teaching critical thinking skills. At the same time, every interviewee presented multiple concerns about logistic, academic, cultural, and technical obstacles challenging the process in a broader sense. Therefore, the results can be considered as subject to debate and discussion among the educational staff, parents and stakeholders due to in terms of the significance of promoting critical thinking and problem solving skills (Polit and Beck, 2010).

These findings suggest the significance of promoting critical thinking within teaching and learning process from different perspectives:

First: Teaching critical thinking in high schools in Kurdistan is an essential tool because these skills lead learners to achieve targeted goals. Individuals will be able to evaluate and analyse complex thoughts rather conforming to different vague but the claimed beliefs.

Second: The Kurdistan Region's education system has attempted to move itself towards modernisation through different phases since 1992, but the impact of traditional trends is still observable due to lack of well-trained modernised staff and the traditional regulations influencing the teaching staff.

Third: Professional development programs for teaching staff and awareness among community members are two significant needs to promote teaching critical thinking.

Fourth: The large number of students and improper buildings, classroom sizes, and facilities and utilities are among the top obstacles challenging the teaching these skills. 
Fifth: The assessment and examination criteria are another challenge facing this process because students' fate and future are determined by unreliable testing methods that encourage memorisation rather self-assessed strategies.

Therefore, the results and findings can be observed throughout the high schools in Kurdistan because the topic is not often reviewed by experts in education. This study considers the ability to generalize the key criteria of the challenges facing the teaching process. As shown above, many teachers note the importance of addressing these challenges to ensure that insights from similar studies and inquiries are recognized as essential sources of indication for practicing the teaching strategies that promote critical thinking skills among students.

\section{Conclusion:}

Finally, the paper reveals most of the challenges and the hurdles facing educators to encourage critical thinking in schools of the Kurdistan region. These skills can be promoted and developed by involving learners in complex activities that require questioning to find solutions. To assist learners to promote these skills and come up with uncommon ideas and solutions, it is extremely crucial for teachers to understand their roles as facilitators. Additionally, the paper identified some strategies to be adapted by the teachers to engage learners in the process. They need to devote time and encourage learners for discussion and validate the different perspectives that emerge because of different thinking.

Secondly, education stakeholders should be required to modernise teachers' approaches of teaching via professional developing programs to promote critical thinking, which are not common in the traditional educational system. As the interviewees highlighted, teachers suffer from lack of support and training programs to enhance these skills. As individuals, teachers experience financial hardship which also directly affects the quality of learning process as whole. 


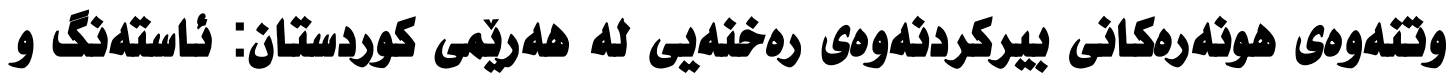 نالاكريدكاز
}

\author{
عزيز رِئوف عبدالعزيز

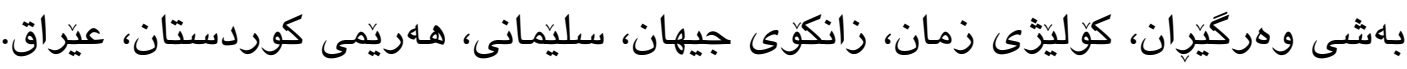 \\ aziz.raouf@sulicihan.edu.krd :يمهيل: \\ شيروان عبدالكريم على

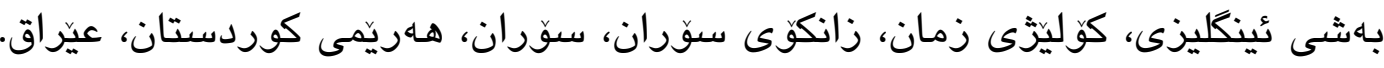 \\ Sirwan.ali@soran.edu.iq :يمهيل'
}

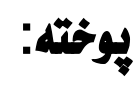

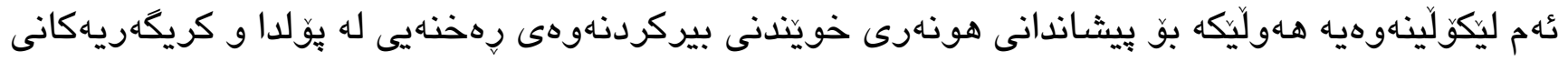
لهسهر قوتابخانه ئامادهييهكانى هـريّمى كوردستانى عيراق. ييناسه بنهرهتيهكان و ستراتيذى تئه كارامهييانه خراوهته رِوو به يشتبه

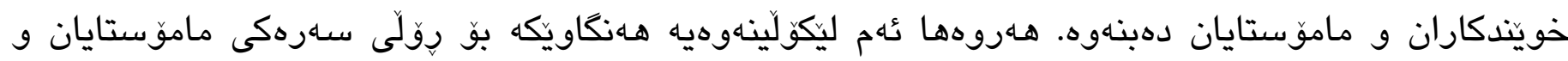

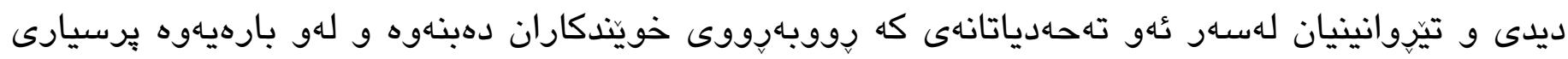

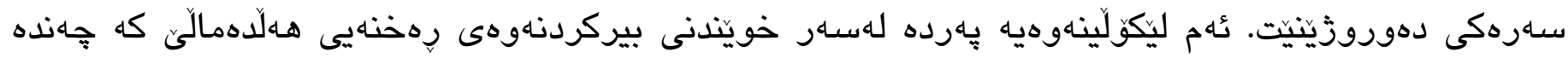

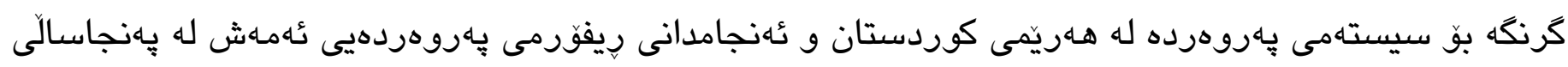
رابردووى سيستهمى يهروهردها روويهرووى دهبيتاهوه. له كهورهترين عالانكارى و تهحهدياتهكان كه

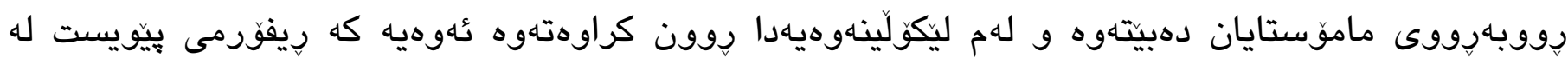

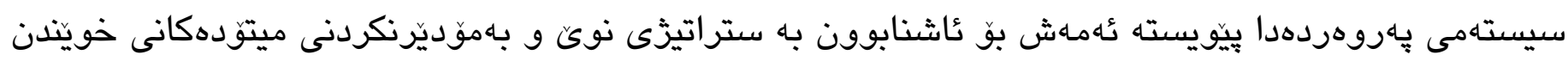

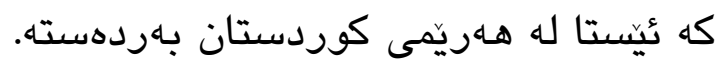

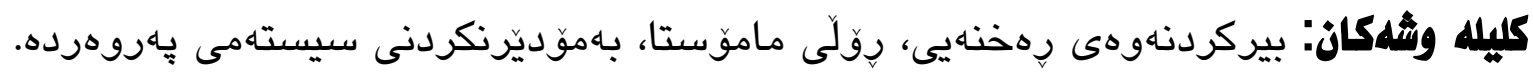




\section{References:}

ALLCHIN, D. 2017. Sacred bovines: The ironies of misplaced assumptions in biology, Oxford University Press.

BROOKFIELD, S. D. 2011. Teaching for critical thinking: Tools and techniques to help students question their assumptions, John Wiley \& Sons.

BROWNE, M. N. \& KEELEY, S. M. 2007. Asking the right questions: A guide to critical thinking, Pearson Education.

CHASE, R. T., JOHANNSEN, K. L., MACINTYRE, P., NAJAFI, K. \& CYNDY, F. 2020. Pathways: Listening, Speaking, and Critical Thinking 4, Cengage Learning.

CHEMI, T. 2017. Distributed Problem-Solving: How Artists' Participatory Strategies Can Inspire Creativity in Higher Education. In: ZHOU, C. (ed.) Handbook of research on creative problem-solving skill development in higher education. IGI global.

CONNELLY, F. M. \& CLANDININ, D. J. 2004. Canadian teacher education in transformation. Reform of teacher education in the Asia-Pacific in the new millennium. Springer.

DIEMER, M. A., RAPA, L. J., VOIGHT, A. M. \& MCWHIRTER, E. H. 2016. Critical consciousness: A developmental approach to addressing marginalization and oppression. Child Development Perspectives, 10, 216-221.

DRISCOLL, A. \& WOOD, S. 2007. Developing outcomes-based assessment for learner-centered education: A faculty introduction, Stylus Publishing, LLC.

DUNN, D. S. 2015. The Oxford handbook of undergraduate psychology education, Oxford University Press.

DZENOVSKA, D. 2018. School of Europeanness: Tolerance and other lessons in political liberalism in Latvia, Cornell University Press.

ELDER, L. \& PAUL, R. 2019. The aspiring thinker's guide to critical thinking, Rowman \& Littlefield.

ELDER, L. \& PAUL, R. 2020. Critical thinking: Tools for taking charge of your learning and your life, Foundation for Critical Thinking.

ENNIS, R. H. 1998. Is critical thinking culturally biased? Teaching philosophy, 21, 15-33.

FREIRE, P. 2009. From pedagogy of the oppressed. Racelethnicity: multidisciplinary global contexts, 2, 163174.

GRAY, F. E. 2010. Specific oral communication skills desired in new accountancy graduates. Business communication quarterly, 73, 40-67.

GREENBERG, J. D., CALKINS, N. \& SPINOSA, L. 2021. Designing and Teaching Fitness Education Courses, Human Kinetics.

HABER, J. 2020. Critical thinking, MIT Press. 
HATTIE, J. 2012. Visible learning for teachers: Maximizing impact on learning, Routledge.

KARWOWSKI, M. \& BRZESKI, A. 2017. Creative mindsets: Prospects and challenges. The creative self. Elsevier.

KLEIN, M. B. 2006. New teaching and teacher issues, Nova Publishers.

MACRITCHIE, F. 2018. The need for critical thinking and the scientific method, CRC Press.

MASATS, D. 2017. Conversation analysis at the service of research in the field of second language acquisition (CA-for-SLA). Qualitative approaches to research on plurilingual education, 321-347.

PAUL, R. 2005. The state of critical thinking today. New directions for community colleges, 2005, 27-38.

PETER, F. \& GITTENS, C. A. 2015. Think Critically.

POLIT, D. F. \& BECK, C. T. 2010. Generalization in quantitative and qualitative research: Myths and strategies. International journal of nursing studies, 47, 1451-1458.

SAMUEL, D. F. 2019. Critical Thinking in Science and Technology: Importance, Rationale, and Strategies. Handbook of Research on Critical Thinking and Teacher Education Pedagogy. IGI Global.

SCHUSTER, S. 2019. The Critical Thinker: The Path To Better Problem Solving, Accurate Decision Making, and Self-Disciplined Thinking, PublishDrive.

VERNEZ, G., CULBERTSON, S., CONSTANT, L. \& KARAM, R. 2016. Initiatives to Improve Quality of Education in the Kurdistan Region-Iraq, RAND Education.

WALKER, B. 2015. Thinking Outside the Box: How to Think Creatively by Applying Critical Thinking and Lateral Thinking, Bruce Walker.

WHITING, L. S. 2008. Semi-structured interviews: guidance for novice researchers. Nursing Standard (through 2013), 22, 35.

YATES, J. F. 1990. Judgment and decision making, Prentice-Hall, Inc. 